\title{
Retention-pH profiles of acids and bases in hydrophilic interaction liquid chromatography
}

Tamara Alvarez-Segura ${ }^{1,2}$, Xavier Subirats ${ }^{1}$, Martí Rosés ${ }^{1, *}$

${ }^{1}$ Institute of Biomedicine (IBUB) and Department of Chemical Engineering and Analytical

Chemistry, Universitat de Barcelona, Martí i Franquès 1-11, 08028 Barcelona, Spain

${ }^{2}$ Department of Analytical Chemistry, University of Valencia, Dr. Moliner 50, 46100

Burjassot (Valencia), Spain

*Corresponding author

Ms. Tamara Alvarez-Segura

E-mail: Tamara.Alvarez@uv.es

Dr. Xavier Subirats

Phone: +34 934039 119, Fax: +34 934021 233, E-mail: xavier.subirats@ub.edu

Prof. Martí Rosés

Phone: +34 934039 275, Fax: +34 934021 233, E-mail: marti.roses@ub.edu 


\begin{abstract}
The high proportion of acetonitrile used in many HILIC mobile phases significantly changes the acid-base properties of $\mathrm{pH}$ buffers and analytes foreseen from available data in water. In this paper, the recommended stability $\mathrm{pH}$ range for chromatographic columns is examined with various acetonitrile water mixtures, resulting in a significant broadening in the operational $\mathrm{pH}$ window with the content of organic solvent. Additionally, the challenge of buffer selection in HILIC is also addressed. Commonly used ammonium acetate shrinks its $\mathrm{pH}$ buffering range in acetonitrile-rich mobile phases due to variations in the dissociation constants of the buffer constituents (acetic acid and ammonium). Thus, other organic acids such as formic acid, TFA, and succinimide have been studied as buffers in order to fully cover the $\mathrm{pH}$ range of use of the column. Also the retention-pH profiles of several acids and bases have been studied in $80 \%$ and $90 \%$ acetonitrile using the proposed buffers and their behavior compared to that obtained with buffers prepared from oxalic acid, pyrrolidine, and triethylamine. The latter two show additional interactions in $80 \%$ acetonitrile that distort the expected retention-pH profiles of acid analytes, but not the ones of bases. In $90 \%$ acetonitrile the profiles are affected by significant additional solute-buffer interactions that might be caused by ion pairing, homo- and heteroassociation in this low ion solvating medium.
\end{abstract}

\title{
Highlights
}

The stability $\mathrm{pH}$ range of a column depends on the mobile phase composition.

The aqueous buffering $\mathrm{pH}$ range of ammonium acetate shrinks in HILIC conditions. Proposed buffers cover the stability $\mathrm{pH}$ range of HILIC columns.

Acid-base reversed-phase partition retention models can be applied to HILIC.

Acetonitrile rich mobile phases shift $\mathrm{p} K_{\mathrm{a}}$ values of analytes and buffering species.

Interactions between ionized analytes and buffers can distort expected retention profiles.

\section{Keywords}

Buffers, chromatographic retention, HILIC, $\mathrm{pH}$ 


\section{Introduction}

The chromatographic retention of acids and bases depends on their ionization, and thus on the $\mathrm{pH}$ of the buffered mobile phase. In reversed-phase liquid chromatography this retention profile has been widely studied by our research group [1-7] and others [8-13]. However, studies about the behavior of ionizable acid-base analytes in HILIC are scarce [14].

McCalley and co-workers investigated the effect of $\mathrm{pH}$ change on retention using ammonium acetate and ammonium formate buffers in the $\mathrm{pH}$ range mainly between 3 and 6 , employing columns of varying nature [15]. In later works [16-18], stronger acids such as phosphoric, trifluoroacetic (TFA), heptafluorobutyric (HFBA) or methanesulfonic (MSA) were considered, as well as ammonium hydrogencarbonate for $\mathrm{pH} 9$. Alpert et al. [19] studied the retention in electrostatic repulsion - hydrophilic interaction chromatography (ERLIC) of peptides with and without a phosphate group, using 70\% acetonitrile mobile phases at several $\mathrm{pH}$ values buffered by triethylammonium phosphate and sodium methylphosphonate, but measuring the $\mathrm{pH}$ prior to the addition of the organic solvent. However, to the best of our knowledge, there is not a systematic study about the variation of the retention of acidic and basic analytes with their ionization in HILIC conditions, i.e. retention vs. $\mathrm{pH}$ profiles.

The retention-pH profiles are difficult to predict from the available thermodynamic aqueous data (i.e. $\mathrm{p} K_{\mathrm{a}}$ ) because the high proportions of organic solvent (commonly acetonitrile) used in HILIC mobile phases modify the aqueous acid-base properties of solvent, buffer and analytes. With the addition of acetonitrile (or other common chromatographic organic solvents) and in reference to pure water, the $\mathrm{pH}$ scale of the solvent is enlarged (from the accepted $\mathrm{pH}$ window $0-14$ in aqueous medium to, for instance, 0-18 in 90\% acetonitrile); the buffered $\mathrm{pH}$ range is shifted, depending on the nature of the buffering agent, and the dissociation degree of the analyte changes according to the variation of its acid-base strength and the change of the buffer $\mathrm{pH}$. In addition to acid-base dissociation and chromatographic distribution of the main neutral and dissociated analyte species, additional interactions might take place, such as ion-pairing or homo- and heteroassociation between analyte and buffer components, caused by the low dielectric constant and poor hydrogen bonding solvating abilities of acetonitrile-rich mobile phases. All these factors need to be addressed to unravel the complex behavior of retention of ionizable acids and bases in HILIC chromatographic systems.

In previous works we have studied the enlargement of the $\mathrm{pH}$ scale of the most common mixed solvents used as LC mobile phases, i.e. acetonitrile/water $[3,20]$ and methanol/water 
[21], and related the methanol/water $\mathrm{pH}$ scale to the operational $\mathrm{pH}$ range of the classic silica based columns used in RP-HPLC, i.e. the $\mathrm{pH}$ limits of use of these columns at the different methanol/water mobile phase compositions [21]. However, the latter was not studied for acetonitrile/water mobile phases, nor for modern HILIC columns, although it can be relatively easily derived from the variation of the autoprotolysis constant of the mobile phase mixed solvent.

The studies about buffers and $\mathrm{pH}$ of the mobile phase are scarce in HILIC [14]. McCalley $[16,17]$ reports the $\mathrm{pH}$ variation of some acidic buffers in acetonitrile/water mixtures, from aqueous solution to nearly $100 \%$ of organic modifier. For a very strong acid in water, such as MSA, a pH of about 2 remains nearly constant up to $80 \%$ acetonitrile, and then slightly increases due to the loss of strength of the acid. In the case of strong acids like TFA or HFBA, this range of constant $\mathrm{pH}$ ends at about $70 \%$ of organic modifier, and then $\mathrm{pH}$ increases more sharply. Finally, for weak acids the $\mathrm{pH}$ increases even at very low concentrations of acetonitrile. There is a need to develop more appropriate buffers for mobile phases with such a high content of organic solvent, especially for the basic $\mathrm{pH}$ region. The acid-base equilibria in acetonitrile/water mixtures have been studied up to $60 \%$ acetonitrile [5,22-26] and even in pure acetonitrile [25,27-30], but the studies in acetonitrile content between 60 and 100\% are very limited [22]. From these works it is clear that only acid-base dissociation equilibria is expected in the range $0-60 \%$ acetonitrile, but that homo- and heteroassociation play also an important role in pure acetonitrile, which affects acid-base dissociation, and these kind of interactions might be expected in acetonitrile-rich mobile phases.

Our purpose is to study the behavior of ionizable acid-base analytes in HILIC columns and buffered mobile phases, and relate the observed retention to the distribution of the different acid-base species in HILIC conditions. Preliminary considerations pointed out the need to know the stability $\mathrm{pH}$ range of the column and set up appropriate $\mathrm{pH}$ buffers for the HILIC conditions. We shall examine these points in this paper for a particular column and different acetonitrile/aqueous buffer mixtures. The retention-pH profiles in the hydroorganic solvent used as mobile phases have been measured for several acids and bases using the proposed buffers in $80 \%$ and $90 \%$ acetonitrile. The equations describing the chromatographic retention from the distribution of the ionized and unionized acid-base species have been fitted to the obtained profiles to check for additional interactions modifying the expected distribution behavior between mobile and stationary phases. The results obtained are 
discussed critically in view of the available knowledge about media similar to these HILIC mobile phases with high acetonitrile contents.

\section{$1.1 \mathrm{pH}$ measurement in hydroorganic mobile phases}

Some authors express the $\mathrm{pH}$ of a hydroorganic mobile phase as the $\mathrm{pH}$ of the aqueous component of the buffer. We strongly discourage this procedure because the addition of organic modifiers can lead to significant changes in the acid-base behavior of the resulting mixed solvent. This is related to the variation in the $\mathrm{p} K_{\mathrm{a}}$ values of buffering species due to the electrostatic interactions between ions and solvent [31]. In the case of a cationic acid (obtained by protonation of a neutral base) the ion species is the protonated molecule (e.g. ammonium), whereas for a neutral acid it is the deprotonated anionic molecule (e.g. acetate). The addition of an organic solvent to water usually leads to a decrease in the relative permittivity of the mixture, increasing the energy required for the solvation of ions, and changing the specific solvation interactions. Therefore, most commonly $\mathrm{p} K_{\mathrm{a}}$ values of cationic acids slightly decrease with the content of organic solvent (i.e. the acid becomes somewhat stronger), whereas neutral and anionic acids show a strong opposite behavior (i.e. increase in $\mathrm{p} K_{\mathrm{a}}$, the acid becoming much weaker) [32]. Consequently, there is a change in the $\mathrm{pH}$ of the buffered solution in agreement with $\mathrm{p} K_{\mathrm{a}}$ variations, which depends on the nature of the buffering species (cationic or neutral/anionic), the content of organic solvent, the initial aqueous $\mathrm{pH}$ and the concentration of the buffer $[33,34]$.

The $\mathrm{pH}$ in the mobile phase can be measured after calibration of the glass electrode system with standards of known $\mathrm{pH}$ prepared exactly in the same solvent composition, or with the conventional aqueous standards, for instance of $\mathrm{pH} 4$ and 7 . Depending on the procedure followed, the former or the latter, the $\mathrm{pH}$ readings are provided in the ${ }_{\mathrm{s}}^{\mathrm{s}} \mathrm{pH}$ or ${ }_{\mathrm{w}}^{\mathrm{s}} \mathrm{pH}$ scales, respectively [35]. The main drawback in the application of ${ }_{\mathrm{s}}^{\mathrm{s}} \mathrm{pH}$ procedure is the need of calibration buffers for each hydroorganic composition and temperature, which are often

unavailable. On the contrary, ${ }_{\mathrm{w}}^{\mathrm{s}} \mathrm{pH}$ can be easily measured since aqueous standard buffers are commercially available and their $\mathrm{pH}$ is well known at several temperatures. Another point in favor of ${ }_{\mathrm{w}}^{\mathrm{s}} \mathrm{pH}$ is that this scale can be converted into ${ }_{\mathrm{s}}^{\mathrm{s}} \mathrm{pH}$ by means of the $\delta$ parameter, which depends on the mixed solvent composition and temperature [36]:

$\delta={ }_{\mathrm{w}}^{\mathrm{s}} \mathrm{pH}-{ }_{\mathrm{s}}^{\mathrm{s}} \mathrm{pH}$ 
It must be pointed out that for acetonitrile/water mixtures $\delta$ quantity can be applied to any ${ }_{\mathrm{w}}^{\mathrm{s}} \mathrm{pH}$ value measured with glass electrode containing a $\mathrm{KCl} 3 \mathrm{M}$ filling solution (salt bridge), in a composition range up to $90 \%$ of organic solvent and temperatures between 15 and $60^{\circ} \mathrm{C}$ [20]. To the best of our knowledge, $\delta$ values have not been measured in the range between 90 and $100 \%$ acetonitrile.

\subsection{Chromatographic retention: mobile phase $\mathrm{pH}$ and analyte $\mathrm{pK} \mathrm{K}_{a}$}

In reversed-phase liquid chromatography the relation between the retention of an analyte with acid-base properties, its acidity constant and the mobile phase is well known $[32,37]$. It is commonly accepted that both reversed-phase and HILIC retention are controlled by liquid-liquid distribution between the mobile phase and the stationary phase, which in HILIC is mainly the aqueous layer accumulated close to the solid surface (although secondary interactions such as hydrogen bonding, dipole-dipole or electrostatic may take place depending on the stationary phase functionalization and analyte characteristics) [38-40]. In the particular case of a monoprotic acid with isocratic elution and constant temperature, the retention factor at any particular $\mathrm{pH}$ is an average of the retention of fully ionized and neutral species weighted by the mole fractions at the particular running $\mathrm{pH}$. Assuming that hold-up times and flow rate remain constant while the mobile phase composition is unchanged, retention volumes $\left(V_{\mathrm{R}}\right)$ or times can be used instead of retention factors leading to the following expression:

$$
V_{\mathrm{R}}=\frac{V_{\mathrm{R}(\mathrm{HX})}+V_{\mathrm{R}(\mathrm{X})} \cdot 10^{\left(\mathrm{pH}-\mathrm{p} K_{\mathrm{a}}\right)}}{1+10^{\left(\mathrm{pH}-\mathrm{p} K_{\mathrm{a}}\right)}}
$$

where $V_{\mathrm{R}(\mathrm{HX})}$ and $V_{\mathrm{R}(\mathrm{X})}$ are the retention volumes (or times) of the fully protonated and deprotonated forms of the acid, respectively, $\mathrm{pH}$ is that measured in the mobile phase $\left({ }_{\mathrm{s}}^{\mathrm{s}} \mathrm{pH}\right.$ or ${ }_{\mathrm{w}}^{\mathrm{s}} \mathrm{pH}$ ), and $\mathrm{p} K_{\mathrm{a}}$ is the acidity constant of the analyte expressed in a scale consistent with the one used for $\mathrm{pH}$. Charges are omitted in the subscripts of Eq. (2) for generalization of the equation. Thus, $\mathrm{HX}$ and $\mathrm{X}$ refers to $\mathrm{HA}$ and $\mathrm{A}^{-}$for a monoprotic neutral acid, and $\mathrm{BH}^{+}$and $\mathrm{B}$ for a monoprotic cationic acid. If the hydrogen activity is measured in the ${ }_{\mathrm{s}}^{\mathrm{s}} \mathrm{pH}$ scale the acidbase constant should be given as ${ }_{\mathrm{s}}^{\mathrm{s}} \mathrm{p} K_{\mathrm{a}}$, and the same reasoning for ${ }_{\mathrm{w}}^{\mathrm{s}} \mathrm{pH}$ and ${ }_{\mathrm{w}}^{\mathrm{s}} \mathrm{p} K_{\mathrm{a}}$ applies. The $\delta$ quantity presented in Eq. (1) is thus also useful for conversion between both $\mathrm{p} K_{\mathrm{a}}$ scales. 
We recommend subtracting extracolumn volume (or time when applicable) for a better interpretation of the fitting parameters $\left(V_{\mathrm{R}(\mathrm{HX})}\right.$ and $\left.V_{\mathrm{R}(\mathrm{X})}\right)$ and comparison with other columns and systems. This approach has been followed in this work, i.e. all retention measurements and results are referred solely to the column.

\section{Materials and methods}

HPLC measurements were performed on Shimadzu (Kyoto, Japan) HPLC systems consisting of: a) two LC-10ADvp pumps, a SIL-10ADvp auto-injector, an SPD-M10AVvp diode array detector, a CTO-10ASvp oven and a SCL-10Avp controller; and b) a LC-20AD pump, a SIL-20AC HT auto-injector, an SPD-10AVvp UV detector set to $220 \mathrm{~nm}$, a CTO10ASvp oven and a DGU-20 A5 degasser. Oven temperature, injection volume and flow rate were set to $25^{\circ} \mathrm{C}, 1 \mu \mathrm{L}$ and $0.50 \mathrm{~mL} \mathrm{~min}^{-1}$ (minimum plate height expected at about $0.2 \mathrm{~mL}$ $\min ^{-1}$ ). These systems were controlled by LCsolutions software (v.1.25) from Shimadzu. The column employed was a $5 \mu \mathrm{m}, 150$ x 4.6 mm ZIC-pHiLIC (Merck, Darmstadt, Germany),

with an operational ${ }_{\mathrm{w}}^{\mathrm{w}} \mathrm{pH}$ range of 2-10. Stock solutions of injected analytes were prepared in methanol at a concentration of $5 \mathrm{mg} \mathrm{mL}^{-1}$ and diluted before injection. Extracolumn times were measured by injection of aqueous solution of $\mathrm{KBr}$ (Merck, $>99 \%$ ) in the absence of the column and using water as eluent, and obtained values were subtracted from gross retention times.

Injected analytes and buffering agents were purchased from Baker, Fluka, Merck, and Sigma-Aldrich, all of high purity grade $(\geq 97 \%)$.

Water was obtained from a Milli-Q plus system (Millipore, Billerica, USA) with a resistivity of $18.2 \mathrm{M} \Omega \mathrm{cm}$. Aqueous buffers were directly prepared by dissolving the solid (ammonium acetate, oxalic acid, sodium hydrogencarbonate, and succinimide) or diluting with water (hydrochloric, formic, phosphoric, and trifluoroacetic acids; pyrrolidine and triethylamine) to a concentration of $50 \mathrm{mM}$, and the final $\mathrm{pH}$ was adjusted by addition of small volumes of concentrated hydrochloric acid or potassium hydroxide solutions. Acetonitrile was HPLC gradient grade from Fisher.

pH was measured using a Crison 5014 combined glass electrode with a salt bridge filled with $3 \mathrm{M} \mathrm{KCl}$ solution, connected to a GLP 22 potentiometer from Crison (Barcelona, Spain). Standard aqueous solutions ( $\mathrm{pH} 4,7$, and 9) were used for calibration.

For the preparation of equimolar solutions of acid and conjugate base, about $0.5 \mathrm{~g}$ of acid was dissolved in water up to $50 \mathrm{~mL}$ with the appropriate volume of a $0.5 \mathrm{M}$ sodium 
hydroxide solution. Then acetonitrile was added to an aliquot of this solution up to $80 \%$ (in volume) and finally $\mathrm{pH}$ was measured after gentle stirring.

\section{Results and discussion}

\subsection{Stability operational $\mathrm{pH}$ range of the column}

Manufacturers always provide information about the stability operational $\mathrm{pH}$ range of supplied LC columns, but this commonly refers to purely aqueous media. Very acidic conditions hydrolyze the support or the stationary phase and excessively basic mobile phases harm the packing. Normally for silica-based columns $\mathrm{pH} 2$ is set out as the lower limit because the rate of hydrolysis of the Si-C bond of silane-based coatings starts to become significant, and generally $\mathrm{pH} 8$ is defined as the alkaline limit due to the dissolution of silica. In the case of unbonded silica or coatings not based on silane chemistry this acidic threshold can be shifted to lower $\mathrm{pH}$ values, and the alkaline stability limit can be improved if an organosilane layer is introduced between the bare silica and the functional groups of the stationary phase. In the case of columns without silica support, the polymer is frequently a manufacturer's proprietary technology. For instance, the operation $\mathrm{pH}$ range that Merck recommends for the ZIC-pHILIC column employed in the present work is 2-10. This $\mathrm{pH}$ range is referred to pure water as solvent. The lowest limit of $\mathrm{pH} 2$ means that mobile phases with $a_{\mathrm{H}^{+}}$higher than $10^{-2}$ should not be used, neither in water nor in any other solvent, including the mixed hydroorganic solvents used as mobile phases (for instance, acetonitrile/water or methanol/water). The alkaline limit of $\mathrm{pH} 10$ in water $\left({ }_{\mathrm{w}}^{\mathrm{w}} \mathrm{pH}_{\max }\right)$ means that the activity of hydroxyl ion $\left(a_{\mathrm{OH}^{-}}\right)$should not be larger than $10^{-4}$, because of the autoprotolysis constant of water $\left(K_{\mathrm{W}}=10^{-14}\right.$ at $25^{\circ} \mathrm{C}$, if $\mathrm{pH}=10, a_{\mathrm{H}^{+}}=10^{-10}$ and $\left.a_{\mathrm{OH}^{-}}=10^{-4}\right)$. This reasoning can be extended to other solvents, either pure or mixed, by means of the following expression:

$$
{ }_{\mathrm{s}}^{\mathrm{s}} \mathrm{pH}_{\max }={ }_{\mathrm{s}}^{\mathrm{s}} \mathrm{p} K_{\mathrm{ap}}-\left(\mathrm{p} K_{\mathrm{w}}-{ }_{\mathrm{w}}^{\mathrm{w}} \mathrm{pH}_{\max }\right)
$$

where ${ }_{\mathrm{s}}^{\mathrm{s}} \mathrm{p} K_{\mathrm{ap}}$ is the negative logarithm of the autoprotolysis constant of the solvent and $\mathrm{p} K \mathrm{w}$ is the one of water (i.e. 14 at $25^{\circ} \mathrm{C}$ ). For instance, in a solvent consisting of $80 \%$ acetonitrile and provided that ${ }_{\mathrm{s}}^{\mathrm{s}} \mathrm{p} K_{\mathrm{ap}}$ has a value of 17.14 [41], the maximum advisable ${ }_{\mathrm{s}}^{\mathrm{s}} \mathrm{pH}$ should be 13.14 instead of the $\mathrm{pH} 10$ in water. 
Several ${ }_{\mathrm{s}}^{\mathrm{s}} \mathrm{p} K_{\text {ap }}$ values for acetonitrile/water mixtures are listed in Table 1, together with $\delta$ parameters allowing the conversion of ${ }_{\mathrm{s}}^{\mathrm{s}} \mathrm{pH}$ values into the ${ }_{\mathrm{w}}^{\mathrm{s}} \mathrm{pH}$ scale (Eq. (1)). These ${ }_{s}^{\mathrm{s}} \mathrm{p} K_{\mathrm{ap}}$ values can be easily used to set up the maximum recommended $\mathrm{pH}$ of HILIC columns.

Figure 1 shows the broadening of the operational $\mathrm{pH}$ range with the addition of acetonitrile. The most common silica based columns employed in HILIC, generally being limited to a $\mathrm{pH}$ range from 2 to 8 in water, experience an increase in the upper $\mathrm{pH}$ limit up to 12.13 in the ${ }_{\mathrm{s}}^{\mathrm{s}} \mathrm{pH}$ scale in mobile phases containing $90 \%$ acetonitrile. If $\mathrm{pH}$ is measured in the ${ }_{w}^{\mathrm{s}} \mathrm{pH}$ scale, due to the influence of the negative value of $\delta$ parameter (Eq. (1)), the minimum ${ }_{\mathrm{w}}^{\mathrm{s}} \mathrm{pH}$ decreases down to 0.24 and the maximum is raised up to 10.37 . As examples, this figure also shows the variation of the most basic recommended $\mathrm{pH}$ value for the ZIC-pHILIC polymeric column used in the present work $(\mathrm{pH} \mathrm{10)}$ and the Kromasil HILIC-D (pH 9.5, which is relatively high for a silica-based packing material).

\subsection{Buffer selection and $\mathrm{pH}$ variation with the addition of acetonitrile}

The selection of an appropriate buffer in HILIC is not straightforward. On the one hand, high contents of organic modifier normally involve solubility issues for ions, especially those of inorganic nature with two or more negative charges (e.g. $\mathrm{HPO}_{4}^{2-}$ or $\mathrm{PO}_{4}^{3-}$ ). On the other hand, the mobile phase $\mathrm{pH}$ might increase or decrease very significantly in relation to the aqueous buffer used in its preparation. For instance, buffers made from formic acid and ammonia might be a very suitable option for MS-friendly mobile phases, either in the acidic or basic $\mathrm{pH}$ range. However, the $\mathrm{p} K_{\mathrm{a}}$ of formic acid shifts up in mixtures with a high content of acetonitrile and thus its suitability of use is significantly reduced in the strongest acidic range. As a general rule, a buffer is suitable in the $\mathrm{pH}$ range corresponding to its $\mathrm{p} K_{\mathrm{a}} \pm 1$ of the acid buffer component, and thus formic acid in water shows a good buffer capacity in the $\mathrm{pH}$ range 2.8-4.8; however, the $\mathrm{p} K_{\mathrm{a}}$ of this acid in, for instance, $60 \%$ acetonitrile is 4.9 [42] and the range of use of this buffer is shifted up to 3.9-5.9. This points out the need of stronger acids than formic acid to buffer the low $\mathrm{pH}$ region. At the other end of the $\mathrm{pH}$ scale, the $\mathrm{p} K_{\mathrm{a}}$ of ammonium shifts down due to its cationic nature, and consequently its range of use is also shifted to a less alkaline region (from 8.3-10.3 in pure aqueous medium to 7.9-10.9 [43]). In this case, a neutral acid of high $\mathrm{p} K_{\mathrm{a}}$ seems to be more adequate because of the increase in the 
$\mathrm{p} K_{\mathrm{a}}$ value with the addition of acetonitrile. Illustrative examples are presented in Figure 2A. An aqueous solution of formic acid of $\mathrm{pH} 3$ leads to a mobile phase ${ }_{\mathrm{w}}^{\mathrm{s}} \mathrm{pH}$ higher than 6 in $95 \%$ acetonitrile. If more acidic mobile phases are required, the relatively weak formic acid should be substituted by the stronger TFA. Ammonium acetate is commonly used as buffering system in HILIC. Between approximately pH 3.5 and 6 the main responsible species for the buffering activity are acetic acid and acetate. Since acetic acid is neutral, the $\mathrm{p} K_{\mathrm{a}}$ of the buffer and consequently the solution ${ }_{\mathrm{w}}^{\mathrm{s}} \mathrm{pH}$ increases with the acetonitrile content. However, above $\mathrm{pH} 8$ the ammonium and ammonia equilibrium takes over, and the $\mathrm{p} K_{\mathrm{a}}$ of the cationic acid and the mobile phase ${ }_{\mathrm{w}}^{\mathrm{s}} \mathrm{pH}$ slightly decrease in relation to aqueous medium. In consequence, the $\mathrm{pH}$ buffered region shrinks from $4-10$ in water $\left(6 \mathrm{pH}\right.$ units) to ${ }_{\mathrm{w}}^{\mathrm{s}} \mathrm{pH} 7-9$ in $90 \%$ acetonitrile (only $2 \mathrm{pH}$ units). Figure $2 \mathrm{~B}$ shows the $\mathrm{pH}$ variation of ammonium acetate buffers in the aqueous $\mathrm{pH}$ range between 4 and 10, those in the neutral to alkaline region being rather stable to variations in the acetonitrile concentration. For the preparation of alkaline mobile phases outside this range a neutral organic acid of relatively high $\mathrm{p} K_{\mathrm{a}}$ such as succinimide should be used instead of the cationic ammonium, since dissociation constants of neutral acids increase with the content of acetonitrile (Figure 2B). In this particular case, boric acid is not a suitable option because of its poor solubility in acetonitrile rich solutions.

Taken into account all these considerations, in addition to ammonium acetate we have selected several organic acids that may be appropriate to study the retention-pH profile of acids and bases in acetonitrile/water mobile phases at the proportions commonly used in HILIC applications. The stability operational $\mathrm{pH}$ range of the column employed (from 2 to 10 in water) can be fully covered with the buffers shown in Figure 2, complemented with the use of stronger acids (hydrochloric and oxalic). Notice that a hydrochloric acid solution of $\mathrm{pH} 2$ in water may decrease to a ${ }_{w}^{\mathrm{s}} \mathrm{pH}$ of 1 at $80 \%$ acetonitrile (and even lower at $90 \%$ ) being still in the operational $\mathrm{pH}$ range of the column, as shown in the figure.

\subsection{Effect of buffer selection and $\mathrm{pH}$ on chromatographic retention}

Figure 3 shows the variation on chromatographic retention of some acids and bases when several buffers were used in $80 \%$ acetonitrile mobile phases. As mentioned earlier, the $\mathrm{pH}$ range of use of a buffer requires the knowledge of its dissociation constant in the particular mobile phase composition employed. In mostly of the cases only aqueous $\mathrm{p} K_{\mathrm{a}}$ 
values are available (Table 2), which will increase or decrease depending on the nature of the acid-base compound but in an extent that cannot be a priori fully predicted. Therefore, $\mathrm{pH}$ values were adjusted directly in the buffered mobile phase by addition of hydrochloric acid or potassium hydroxide, and the $\mathrm{pH}$ was checked periodically in the eluate in order to assess a good buffer capacity leading to a constant mobile phase $\mathrm{pH}$. For both the acidic and basic analytes, retention times obtained using mobile phases prepared from ammonium acetate and hydrochloric, oxalic, and formic acids allowed nice fits to Eqs. (2) with determination coefficients $\geq 0.97$ (Table 3 ). Due to the high $\mathrm{p} K_{\mathrm{a}}$ value of phenol at $80 \%$ acetonitrile, the retention of the ionized species could not be determined and it is not reported in Table 3. Moreover, the fitted $\mathrm{p} K_{\mathrm{a}}$ value has a high uncertainty. The observed retention profiles (Figure 3) are the inverse of those expected in reversed-phase, since in HILIC positively and negatively charged compounds are more retained than neutral ones. It is noteworthy that all buffers in the alkaline region can be used in the fitting of retention of neutral bases, but not for the neutral acids. Retention of benzoic acid, ibuprofen, 4-nitrophenol, and phenol in succinimide, pyrrolidine, and triethylamine buffers is clearly much lower than that obtained for ammonium buffers. It may be argued that the right expected retention vs. $\mathrm{pH}$ profile is that measured from succinimide, pyrrolidine, and triethylamine buffers, and consequently the retention in ammonium buffers is higher than expected. However, this speculation is not in agreement with experimental $\mathrm{pH}$ measurements of the tested acids.

With a view to verify the correctness of the buffers actually selected for the fitting of acidic compounds to Eq. (2) in Figure 3 and Table 3, ${ }_{\mathrm{w}}^{\mathrm{s}} \mathrm{p} K_{\mathrm{a}}$ fits were compared to measured ${ }_{\mathrm{w}}^{\mathrm{s}} \mathrm{pH}$ values of equimolar mixtures of acid and conjugate base of the analyte. For a particular compound and according to the expression of its acidity constant, the $\mathrm{pH}$ measured in a solution containing the same concentration of acid and conjugate base should be reasonably close to the $\mathrm{p} K_{\mathrm{a}}$ value (although not exactly because in solvents containing a relatively high content of acetonitrile the activity coefficient of the ion is expected to be different from 1). In fact, as shown in Table 4, measured ${ }_{\mathrm{w}}^{\mathrm{s}} \mathrm{pH}$ and fitted ${ }_{\mathrm{w}}^{\mathrm{s}} \mathrm{p} K_{\mathrm{a}}$ values match quite well, and therefore this indicates that retention obtained with succinimide, pyrrolidine, and triethylamine buffers was influenced by additional interactions not considered in the actual retention model. For the two latter buffers these deviations might be attributed to ion pairing of the acid anion with the buffer cation, which may be not meaningless in acetonitrile rich compositions as explained later. As pointed out by Alpert [44] the degree of hydration of the counterion is a critical variable in retention of charged analytes in HILIC. However, the 
reasons for the different behaviors observed for succinimide in the present study are still unclear and require further investigation.

Hydrochloric and oxalic acids were used in the preparation of mobile phases of $\mathrm{pH}$ around 1 just because of the broadening of the operational $\mathrm{pH}$ range of the column with the addition of acetonitrile, as shown in Figure 2.

Regarding differences between aqueous $\mathrm{p} K_{\mathrm{a}}$ and ${ }_{\mathrm{w}}^{\mathrm{s}} \mathrm{p} K_{\mathrm{a}}$ values obtained from retention data measured at 80 and $90 \%$ acetonitrile, the expected different behavior between cationic and neutral acids was clearly observed (Table 4 ). For acids there was a $\mathrm{p} K_{\mathrm{a}}$ increase in the range from 1.45 (4-nitrophenol) to 2.64 (ibuprofen), and for bases there was a decrease between 0.45 (atenolol) and 2.00 (lidocaine) $\mathrm{p} K_{\mathrm{a}}$ units. There are equations that allow an estimation of $\mathrm{p} K_{\mathrm{a}}$ values in acetonitrile/water mixtures for the most common families of analytes (aromatic and aliphatic carboxylic acids, phenols, amines, and pyridines), but only up to $60 \%$ of organic modifier ( $100 \%$ for pyridines) [25,33], and thus they cannot be applied to the present mobile phases. The observed $\mathrm{p} K_{\mathrm{a}}$ variations are in accordance to those that might be expected for $80 \%$ and $90 \%$ acetonitrile.

Retention profiles were also assessed with a higher content of acetonitrile (90\%) using the buffers that showed good fits to Eq. (2) at $80 \%$ of organic modifier, and additionally trifluoroacetic acid was included in the study in order to solve eventual solubility problems with oxalate. Results are presented in Figure 4 . The trend in the $\mathrm{p} K_{\mathrm{a}}$ shifts of analytes observed at $80 \%$ acetonitrile was maintained (Table 4), with that of phenol being so extreme $(>12.5)$ that only retention times of neutral species could be obtained in the studied $\mathrm{pH}$ range. As expected, retention times of positively charged cationic acids were especially low when trifluoroacetic acid was introduced in the mobile phase, most probably due to ion pairing of the cationic analyte with the poorly hydrated trifluoroacetate ion [44]. This was not the case when neutral acids were considered. However, generally worse fits were obtained at $90 \%$ acetonitrile, suggesting that ion pair formation, homo- and heteroassociation might occur at such a high concentration of organic modifier.

Pure acetonitrile is a dipolar solvent, with large dipole moments but a moderate relative permittivity, allowing a limited ability to solvate ions and leading to a tendency for ion pair formation. Acetonitrile is also apolar, with virtually no acid-base properties and consequently with a small autoprotolysis constant, and a very poor hydrogen-bonding solvent. Therefore, because of this protophobic nature, neutral acids with hydrogen bond donor properties are poorly stabilized in acetonitrile, leading to hydrogen bonding with its conjugated anionic base 
(homoassociation) or with a non-conjugated anion (heteroassociation) [27] (notice that the terms homo- and heteroassociation are used here instead of homo- and heteroconjugation in agreement with IUPAC recommendations [45]). In fact, heteroassociation between neutral acids and alcohols with relatively small anions (e.g. chloride, perchlorate) has been described as a separation mechanism in non-aqueous capillary electrophoresis [46]. Homoassociation for cationic acids and their conjugate neutral bases has also been reported in the literature [27]. Although the presence of small amounts of water increases the relative permittivity of the mixture and significantly raises its hydrogen bonding capabilities, thus reducing the extent of association interactions, they might not be negligible in $90 \%$ acetonitrile and might explain the complex behavior of retention profiles in these mobile phases. Studies are in progress to confirm or refute this speculation.

Although acetonitrile is by far the most widely used organic solvent in HILIC, others such as methanol, propanol, acetone or tetrahydrofuran have also been employed. For these less common organic solvents and depending on their nature, some changes in the ionization and buffering effects should be expected in relation to acetonitrile.

\section{Conclusions}

HILIC mobile phases require a high content of organic solvent that changes the acidbase properties of the solvent medium, $\mathrm{pH}$ buffers and measured analytes. As a consequence of the decrease in the autoprotolysis constant, the operational $\mathrm{pH}$ range of chromatographic columns broadens with the content of acetonitrile in the mobile phase. When measured in the ${ }_{w}^{\mathrm{s}} \mathrm{pH}$ scale, which uses water as standard reference solvent, the recommended alkaline $\mathrm{pH}$ limit for column stability is raised by more than $2 \mathrm{pH}$ units in relation to the limit in water, and the suggested lower limit for $\mathrm{pH}$ drops $1.8 \mathrm{pH}$ units at $90 \%$ acetonitrile. Hence, the stability operational $\mathrm{pH}$ range of the column is broadened by $3.8 \mathrm{pH}$ units. Also, the changes in relative permittivity and acid-base properties of the solvent medium increases the $\mathrm{p} K_{\mathrm{a}}$ of neutral acids and slightly decreases the $\mathrm{p} K_{\mathrm{a}}$ of neutral bases, which modifies the $\mathrm{pH}$ range covered by $\mathrm{pH}$ buffers. For instance, the common ammonium acetate buffer used to cover the 4-10 $\mathrm{pH}$ range in water, is only suitable for the much smaller 7-9 $\mathrm{pH}$ range in $90 \%$ acetonitrile. The $\mathrm{pH}$ range below 6 can be easily covered by other organic acids stronger than acetic acid, such as formic acid, and with even stronger ones as oxalic, trifluoroacetic or hydrochloric acids. Because of the decrease of the $\mathrm{p} K_{\mathrm{a}}$ of neutral bases and the solubility 
problems of inorganic acids, organic acids (for instance, succinimide in this work) are proposed as suitable buffers for the basic $\mathrm{pH}$ range ( $\mathrm{pH}>9.5$ in $90 \%$ acetonitrile).

The retention-pH profiles of several acidic and basic analytes have been studied in $80 \%$ and $90 \%$ acetonitrile mobile phases using the buffers proposed above and a polymeric zwitterionic column. If ion pairing and other specific interactions between analytes and buffer components are negligible, variation of chromatographic retention with mobile phase $\mathrm{pH}$ can be modeled in HILIC using the same type of equations described for reversed-phase mode, but with the characteristic of the ionized species being more retained than the neutral one. Buffers should be accurately selected because their aqueous $\mathrm{p} K_{\mathrm{a}}$ values, and consequently the buffered $\mathrm{pH}$ range, may shift very significantly depending on the buffer nature (cationic or neutral acids) and the mobile phase composition. Additionally, in mobile phases with a high content of acetonitrile ion pairing may take place between cationic analytes and anionic buffer components (trifluoroacetate) or anionic analytes and cationic buffering species (pyrrolidinium and triethylammonium). In these mobile phases the observed retention is lower than expected. 


\section{ACKNOWLEDGEMENTS}

This work was supported by the Ministry of Economy, Industry and Competitiveness of Spain (project CTQ2017-88179-P AEI/FEDER, UE). The authors thank Merck KGaA (Darmstadt, Germany) and Dr. Patrik Appelblad for providing the SeQuant ZIC-pHILIC column. Tamara Alvarez-Segura thanks the projects CTQ2016-75644-P (Ministry of Economy and Competitiveness of Spain), PROMETEO/2016/128 (Generalitat Valenciana, Spain), and UV INV-PREDOC16F1-383078 (University of Valencia).

\section{CONFLICT OF INTEREST STATEMENT}

The authors declare no conflict of interest. 
TABLES

Table 1. Autoprotolysis constants for acetonitrile/water mixtures and $\delta$ parameters for the conversion of ${ }_{\mathrm{s}}^{\mathrm{s}} \mathrm{pH}$ into ${ }_{\mathrm{w}}^{\mathrm{s}} \mathrm{pH}$ scale at $25^{\circ} \mathrm{C}[20,41]$.

\begin{tabular}{ccc}
\hline$\% \mathrm{ACN}(\mathrm{v} / \mathrm{v})$ & ${ }_{\mathrm{s}}^{\mathrm{s}} \mathrm{p} K_{\mathrm{ap}}$ & $\delta$ \\
\hline 0 & 14.00 & 0.00 \\
10 & 14.22 & -0.04 \\
20 & 14.48 & -0.08 \\
30 & 14.76 & -0.14 \\
40 & 15.08 & -0.21 \\
50 & 15.46 & -0.30 \\
60 & 15.90 & -0.43 \\
70 & 16.44 & -0.63 \\
80 & 17.14 & -0.98 \\
90 & 18.13 & -1.76 \\
100 & $>32.4$ & - \\
\hline
\end{tabular}

Table 2. Aqueous $\mathrm{p} K_{\mathrm{a}}$ values of buffers studied in the present work at $25^{\circ} \mathrm{C}$ [47].

\begin{tabular}{lclc}
\hline Buffer & $\mathrm{p} K_{\mathrm{a}}$ & Buffer & $\mathrm{p} K_{\mathrm{a}}$ \\
\hline Trifluoroacetic acid & 0.52 & Ammonium & 9.25 \\
Oxalic acid & $1.25,3.81$ & Succinimide & 9.62 \\
Formic acid & 3.75 & Triethylamine & 10.75 \\
Acetic acid & 4.76 & Pyrrolidine & 11.31 \\
\hline
\end{tabular}


Table 3. Fitted retention volumes and pKa values to Eq. (2) for the studied compounds in mobile phases containing 80 and $90 \%$ acetonitrile, together with the standard errors of the fittings and the determination coefficients.

\begin{tabular}{|c|c|c|c|c|c|c|c|c|c|c|}
\hline \multirow[b]{2}{*}{ Analyte } & \multicolumn{5}{|c|}{$80 \%(\mathrm{v} / \mathrm{v})$} & \multicolumn{5}{|c|}{$90 \%(\mathrm{v} / \mathrm{v})$} \\
\hline & $V_{\mathrm{R}(\mathrm{HX})} / \mathrm{mL}$ & $V_{\mathrm{R}(\mathrm{X})} / \mathrm{mL}$ & $\mathrm{p} K_{\mathrm{a}}$ & Fit $S E$ & $R^{2}$ & $V_{\mathrm{R}(\mathrm{HX})} / \mathrm{mL}$ & $V_{\mathrm{R}(\mathrm{X})} / \mathrm{mL}$ & $\mathrm{p} K_{\mathrm{a}}$ & Fit $S E$ & $R^{2}$ \\
\hline Benzoic acid & $1.53(0.01)$ & $3.09(0.01)$ & $6.35(0.03)$ & 0.04 & 0.999 & $1.63(0.33)$ & $8.38(0.28)$ & 7.14(0.12) & 0.86 & 0.986 \\
\hline Ibuprofen & $1.25(0.01)$ & $1.54(0.01)$ & $6.91(0.10)$ & 0.03 & 0.990 & $1.35(0.10)$ & $2.84(0.11)$ & $7.66(0.17)$ & 0.30 & 0.964 \\
\hline 4-Nitrophenol & $1.51(0.01)$ & $2.35(0.03)$ & $8.60(0.12)$ & 0.07 & 0.989 & $1.65(0.02)$ & $4.82(0.17)$ & $9.61(0.08)$ & 0.10 & 0.998 \\
\hline Phenol & $1.54(0.03)$ & - & $12.56(48)$ & 0.98 & 0.981 & - & - & - & - & - \\
\hline Lidocaine & $2.10(0.03)$ & $1.23(0.02)$ & $5.92(0.12)$ & 0.11 & 0.985 & $2.62(0.11)$ & $1.32(0.06)$ & $6.03(0.18)$ & 0.23 & 0.968 \\
\hline Mepivacaine & $2.19(0.03)$ & $1.30(0.04)$ & $6.84(0.14)$ & 0.14 & 0.978 & $3.18(0.17)$ & $1.42(0.12)$ & $6.77(0.24)$ & 0.41 & 0.952 \\
\hline Bupivacaine & $1.53(0.01)$ & $1.18(0.02)$ & $7.30(0.11)$ & 0.05 & 0.978 & $2.02(0.09)$ & $1.26(0.08)$ & $7.14(0.28)$ & 0.23 & 0.923 \\
\hline Propranolol & $2.14(0.03)$ & $1.22(0.06)$ & $8.95(0.18)$ & 0.15 & 0.973 & $3.60(0.36)$ & $1.15(0.82)$ & $8.77(0.63)$ & 1.38 & 0.725 \\
\hline Atenolol & $3.06(0.05)$ & $1.38(0.11)$ & $9.15(0.17)$ & 0.28 & 0.967 & 10.61(1.36) & $0.95(3.44)$ & $8.92(0.64)$ & 5.43 & 0.709 \\
\hline
\end{tabular}


Table 4. Aqueous $\mathrm{p} K_{\mathrm{a}}$, fitted ${ }_{\mathrm{w}}^{\mathrm{s}} \mathrm{p} K_{\mathrm{a}}$ (Eq. (2)) from retention data and measured ${ }_{\mathrm{w}}^{\mathrm{s}} \mathrm{pH}$ of equimolar solutions of acid analytes in solutions containing acetonitrile.

\begin{tabular}{|c|c|c|c|c|}
\hline \multirow[b]{2}{*}{ Analyte } & \multirow{2}{*}{$\frac{\text { Water }}{\mathrm{p} K_{\mathrm{a}}}$} & \multicolumn{2}{|c|}{$80 \%(\mathrm{v} / \mathrm{v})$} & \multirow{2}{*}{$\frac{90 \%(\mathrm{v} / \mathrm{v})}{\text { Fitted }{ }_{\mathrm{w}}^{\mathrm{s}} \mathrm{p} K_{\mathrm{a}}}$} \\
\hline & & Fitted ${ }_{\mathrm{w}}^{\mathrm{s}} \mathrm{p} K_{\mathrm{a}}$ & Equimolar ${ }_{\mathrm{w}}^{\mathrm{s}} \mathrm{pH}$ & \\
\hline Benzoic acid & $4.20^{\mathrm{a}}$ & 6.4 & 6.7 & 7.1 \\
\hline Ibuprofen & $4.27^{b}$ & 6.9 & 7.2 & 7.7 \\
\hline 4-Nitrophenol & $7.15^{\mathrm{a}}$ & 8.6 & 9.1 & 9.6 \\
\hline Phenol & $9.99^{\mathrm{a}}$ & 12.6 & 12.5 & - \\
\hline Lidocaine & $7.89^{b}$ & 5.9 & - & 6.0 \\
\hline Mepivacaine & $7.92^{b}$ & 6.8 & - & 6.7 \\
\hline Bupivacaine & $8.10^{\mathrm{b}}$ & 7.3 & - & 6.9 \\
\hline Propranolol & $9.47^{b}$ & 9.0 & - & 8.8 \\
\hline Atenolol & $9.60^{b}$ & 9.2 & - & 8.9 \\
\hline
\end{tabular}

${ }^{\mathrm{a}}$ From ref. [47]. ${ }^{\mathrm{b}}$ From ref. [48]. 


\section{FIGURES}

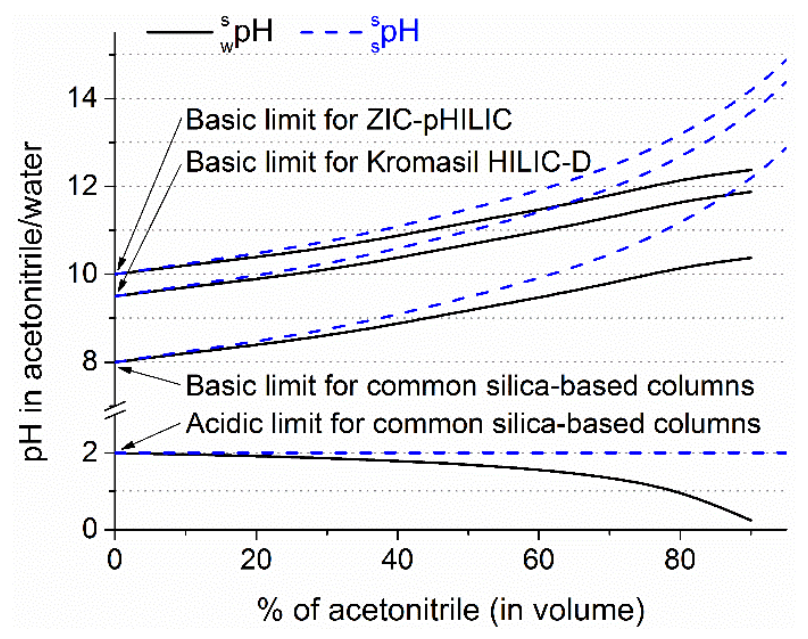

Figure 1. Calculated variations in the stability $\mathrm{pH}$ limits (acidic and basic) of LC columns with acetonitrile content when $\mathrm{pH}$ is expressed as ${ }_{\mathrm{w}}^{\mathrm{s}} \mathrm{pH}$ or ${ }_{\mathrm{s}}^{\mathrm{s}} \mathrm{pH}$. ZIC-pHILIC is a zwitterionic (sulphobetaine) polymeric column, and Kromasil HILIC-D consists of dihydroxypropane groups chemically bonded to porous silica particles. 

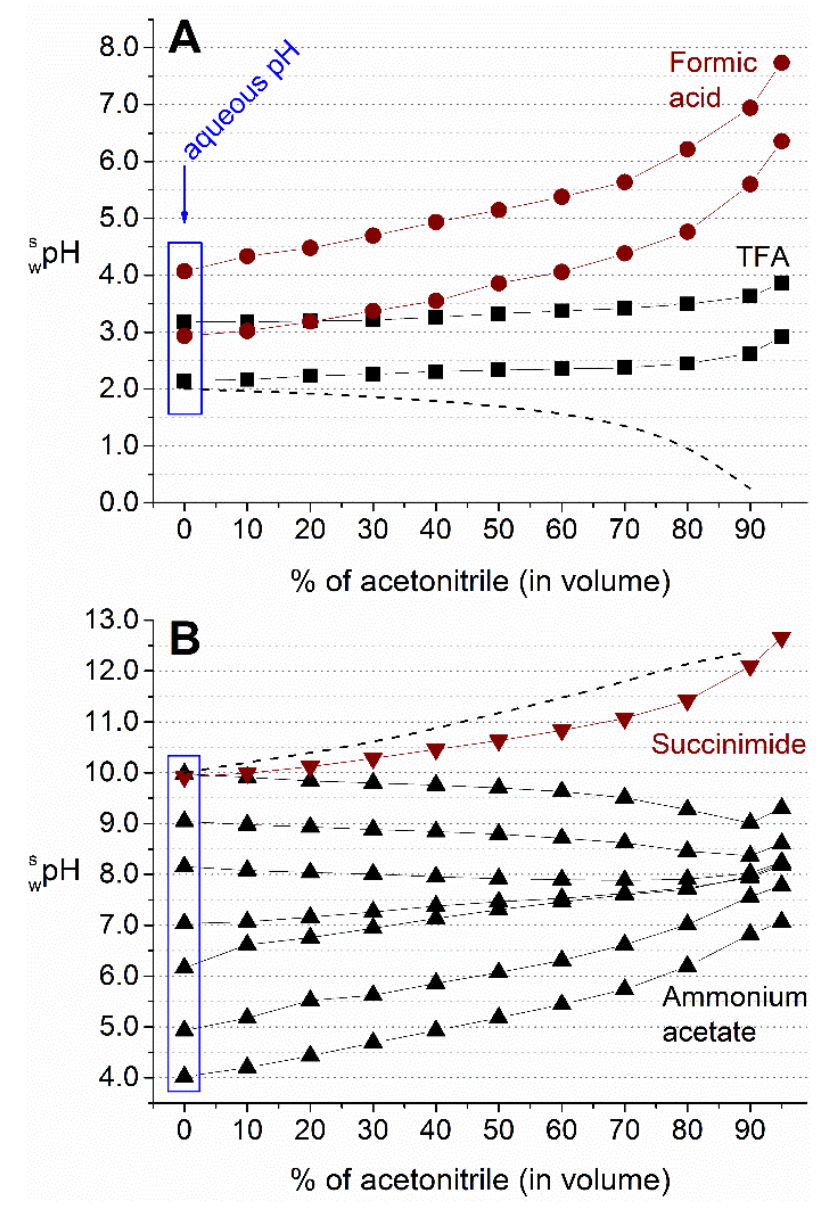

Figure 2. Measured $\mathrm{pH}$ variations with the addition of acetonitrile to $50 \mathrm{mM}$ aqueous solutions of buffers prepared from (A) TFA ( $\bullet$ ) and formic acid (•), and (B) ammonium acetate $(\boldsymbol{\Delta})$ and succinimide $(\boldsymbol{\nabla})$. Dashed lines represent the recommended lower and maximum $\mathrm{pH}$ values for the column employed in the present work. 

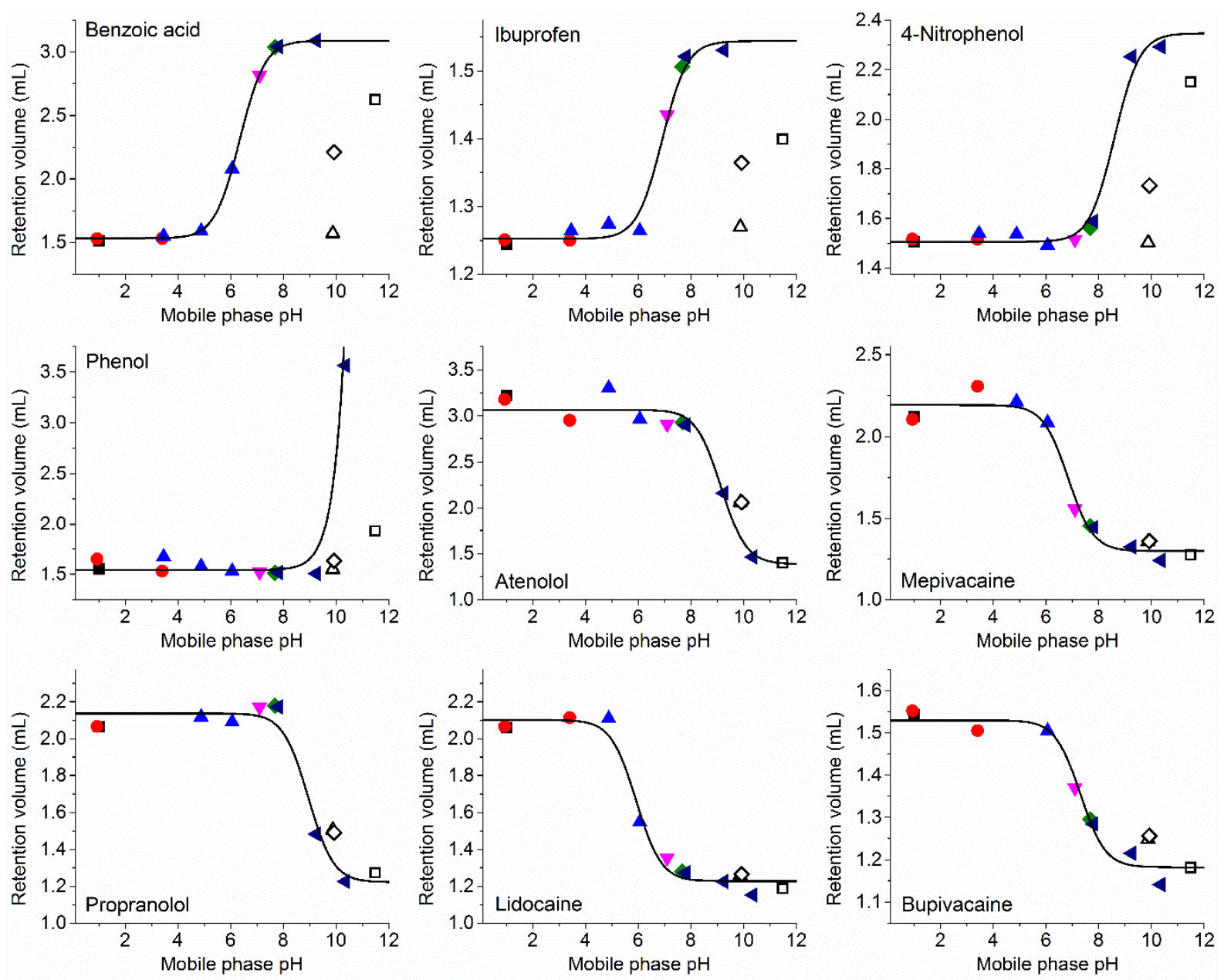

- $\mathrm{HCl}$

- Oxalic acid+KOH

口 Succinimide $+\mathrm{KOH}$

$\triangle$ Pyrrolidine $+\mathrm{HCl} \diamond$ Triethylamine $+\mathrm{HCl}$

Figure 3. Variation of retention times of some acidic and basic analytes with the ${ }_{w}^{\mathrm{s}} \mathrm{pH}$ of a mobile phase containing $80 \%$ (by volume) of acetonitrile and prepared from different buffers. Empty symbols were excluded in the fittings to Eqs. (2). 

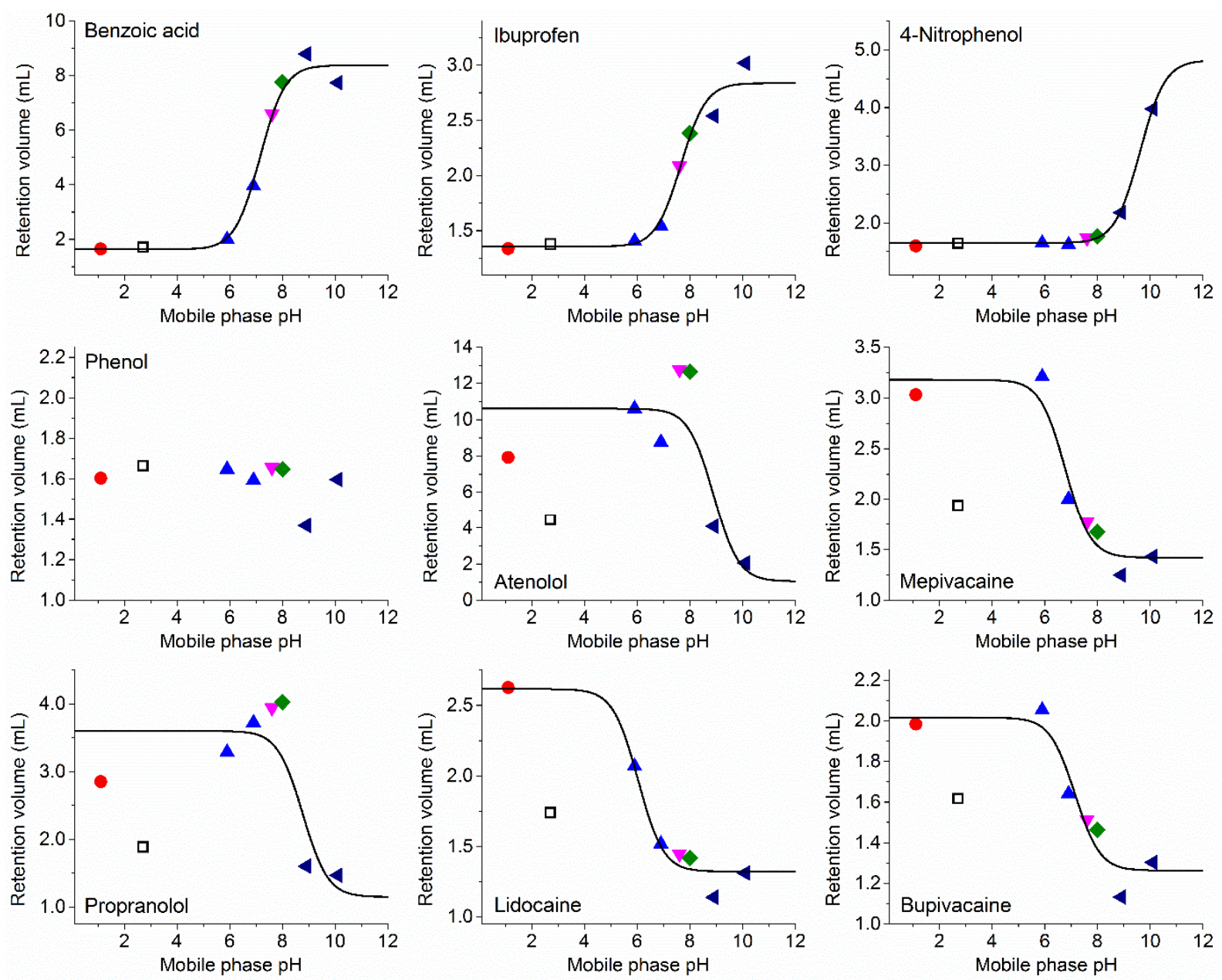

- Oxalic acid+KOH $\square \mathrm{TFA}+\mathrm{KOH}$

- $\mathrm{HCOOH}+\mathrm{KOH} \nabla \mathrm{NH}_{4} \mathrm{CH}_{3} \mathrm{COO}+\mathrm{HCl}$

$\mathrm{NH}_{4} \mathrm{CH}_{3} \mathrm{COO}$

$\mathrm{NH}_{4} \mathrm{CH}_{3} \mathrm{COO}+\mathrm{KOH}$

Figure 4. Retention times vs. mobile phase ${ }_{\mathrm{w}}^{\mathrm{s}} \mathrm{pH}$ in isocratic elution at $90 \%$ acetonitrile. 


\section{LITERATURE}

[1] M. Rosés, I. Canals, H. Allemann, K. Siigur, E. Bosch, Retention of ionizable compounds on HPLC. 2. Effect of $\mathrm{pH}$, ionic strength, and mobile phase composition on the retention of weak acids, Anal. Chem. 68 (1996) 4094-4100. doi:10.1021/ac960105d.

[2] I. Canals, J.A. Portal, E. Bosch, M. Rosés, Retention of ionizable compounds on HPLC. 4. Mobile-phase pH measurement in methanol/water, Anal. Chem. 72 (2000) 1802-1809. doi:10.1021/ac990943i.

[3] S. Espinosa, E. Bosch, M. Rosés, Retention of ionizable compounds on HPLC. 5. pH scales and the retention of acids and bases with acetonitrile-water mobile phases, Anal. Chem. 72 (2000) 5193-5200. doi:10.1021/ac000591b.

[4] I. Canals, F.Z. Oumada, M. Rosés, E. Bosch, Retention of ionizable compounds on HPLC. 6. pH measurements with the glass electrode in methanol-water mixtures, J. Chromatogr. A. 911 (2001) 191-202. doi:10.1016/S0021-9673(00)01271-1.

[5] S. Espinosa, E. Bosch, M. Rosés, Retention of ionizable compounds in highperformance liquid chromatography. IX. Modelling retention in reversed-phase liquid chromatography as a function of $\mathrm{pH}$ and solvent composition with acetonitrile-water mobile phases, J. Chromatogr. A. 947 (2002) 47-58. doi:10.1016/S00219673(01)01597-7.

[6] I. Canals, J. a. Portal, M. Rosés, E. Bosch, Retention of ionizable compounds on HPLC. Modelling retention in reversed-phase liquid chromatography as a function of pH and solvent composition with methanol-water mobile phases, Chromatographia. 55 (2002) 565-571. doi:10.1007/BF02492902.

[7] X. Subirats, E. Bosch, M. Rosés, Retention of ionisable compounds on highperformance liquid chromatography. XVI. Estimation of retention with acetonitrile/water mobile phases from aqueous buffer $\mathrm{pH}$ and analyte $\mathrm{p} K_{\mathrm{a}}, \mathrm{J}$. Chromatogr. A. 1121 (2006) 170-177. doi:10.1016/j.chroma.2006.03.126.

[8] D. Sýkora, E. Tesařová, M. Popl, Interactions of basic compounds in reversed-phase high-performance liquid chromatography. Influence of sorbent character, mobile phase composition, and $\mathrm{pH}$ on retention of basic compounds, J. Chromatogr. A. 758 (1997) 37-51. doi:10.1016/S0021-9673(96)00691-7.

[9] R. Bergés, V. Sanz-Nebot, J. Barbosa, Modelling retention in liquid chromatography as 
a function of solvent composition and $\mathrm{pH}$ of the mobile phase, J. Chromatogr. A. 869 (2000) 27-39. doi:https://doi.org/10.1016/S0021-9673(99)00915-2.

[10] J.J. Baeza-Baeza, M.C. García-Alvarez-Coque, Some observations on the prediction of retention in reversed-phase liquid chromatography using the $\mathrm{pH}$ as main factor, Anal. Chim. Acta. 521 (2004) 61-68. doi:10.1016/j.aca.2004.05.035.

[11] R. Kaliszan, P. Wiczling, M.J. Markuszewski, pH gradient high-performance liquid chromatography: Theory and applications, J. Chromatogr. A. 1060 (2004) 165-175. doi:10.1016/j.chroma.2004.04.081.

[12] N. Sanli, G. Fonrodona, J. Barbosa, G.A. Özkan, J.L. Beltran, Modelling retention in liquid chromatography of polyphenolic acids: Prediction of solvent composition and pH of the mobile phase, Anal. Chim. Acta. 537 (2005) 53-61. doi:10.1016/j.aca.2005.01.006.

[13] P. Wiczling, R. Kaliszan, Influence of $\mathrm{pH}$ on retention in linear organic modifier gradient RP HPLC, Anal. Chem. 80 (2008) 7855-7861. doi:10.1021/ac801093u.

[14] D. V. McCalley, Understanding and manipulating the separation in hydrophilic interaction liquid chromatography-a review, J. Chromatogr. A. 1523 (2017) 49-71. doi:10.1016/j.chroma.2017.06.026.

[15] A. Kumar, J.C. Heaton, D. V. McCalley, Practical investigation of the factors that affect the selectivity in hydrophilic interaction chromatography, J. Chromatogr. A. 1276 (2013) 33-46. doi:10.1016/j.chroma.2012.12.037.

[16] D. V. McCalley, Study of retention and peak shape in hydrophilic interaction chromatography over a wide pH range, J. Chromatogr. A. 1411 (2015) 41-49. doi:10.1016/j.chroma.2015.07.092.

[17] D. V. McCalley, Effect of mobile phase additives on solute retention at low aqueous pH in hydrophilic interaction liquid chromatography, J. Chromatogr. A. 1483 (2017) 71-79. doi:10.1016/j.chroma.2016.12.035.

[18] D. V. McCalley, A study of the analysis of acidic solutes by hydrophilic interaction chromatography, J. Chromatogr. A. 1534 (2018) 64-74. doi:10.1016/j.chroma.2017.12.045.

[19] A.J. Alpert, O. Hudecz, K. Mechtler, Anion-exchange chromatography of phosphopeptides: Weak anion exchange versus strong anion exchange and anionexchange chromatography versus electrostatic repulsion-hydrophilic interaction 
chromatography, Anal. Chem. 87 (2015) 4704-4711. doi:10.1021/ac504420c.

[20] L.G. Gagliardi, C.B. Castells, C. Ràfols, M. Rosés, E. Bosch, $\delta$ Conversion Parameter between $\mathrm{pH}$ Scales ( and ) in Acetonitrile/Water Mixtures at Various Compositions and Temperatures, Anal. Chem. 79 (2007) 3180-3187. doi:10.1021/ac062372h.

[21] E. Bosch, P. Bou, H. Allemann, M. Rosés, Retention of ionizable compounds on HPLC. $\mathrm{pH}$ Scale in methanol-water and the $\mathrm{pK}$ and $\mathrm{pH}$ values of buffers, Anal. Chem. 68 (1996) 3651-3657. doi:10.1021/ac9601041.

[22] Z. Pawlak, Solvent effects on acid-base behaviour Acidity constants of eight protonated substituted pyridines in (acetonitrile+water), J. Chem. Thermodyn. 19 (1987) 443-447. doi:10.1016/0021-9614(87)90129-7.

[23] E. Bosch, S. Espinosa, M. Rosés, Retention of ionizable compounds on highperformance liquid chromatography. III. Variation of $\mathrm{pK}$ values of acids and $\mathrm{pH}$ values of buffers in acetonitrile-water mobile phases, J. Chromatogr. A. 824 (1998) 137-146. doi:10.1016/S0021-9673(98)00647-5.

[24] K. Sarmini, E. Kenndler, Capillary zone electrophoresis in mixed aqueous-organic media: effect of organic solvents on actual ionic mobilities and acidity constants of substituted aromatic acids, J. Chromatogr. A. 833 (1999) 245-259. doi:10.1016/S00219673(98)00984-4.

[25] S. Espinosa, E. Bosch, M. Rosés, Retention of ionizable compounds in highperformance liquid chromatography. 14. Acid-base $\mathrm{p} K$ values in acetonitrile-water mobile phases, J. Chromatogr. A. 964 (2002) 55-66. doi:10.1016/S00219673(02)00558-7.

[26] S. Espinosa, E. Bosch, M. Rosés, Acid-base constants of neutral bases in acetonitrilewater mixtures, Anal. Chim. Acta. 454 (2002) 157-166. doi:10.1016/S00032670(01)01541-0.

[27] I.M. Kolthoff, Acid-base equilibriums in dipolar aprotic solvents, Anal. Chem. 46 (1974) 1992-2003. doi:10.1021/ac60349a005.

[28] K. Izutsu, Acid-base dissociation constants in dipolar aprotic solvents, Blackwell Scientific, Oxford, 1990.

[29] D. Augustin-Nowacka, L. Chmurzyñski, A potentiometric study of acid-base equilibria of substituted pyridines in acetonitrile, Anal. Chim. Acta. 381 (1999) 215-220. doi:10.1016/S0003-2670(98)00771-5. 
[30] K. Sarmini, E. Kenndler, Ionization constants of weak acids and bases in organic solvents, J. Biochem. Biophys. Methods. 38 (1999) 123-137. doi:10.1016/S0165022X(98)00033-5.

[31] L. Šůcha, S. Kotrlý, Solution equilibria in analytical chemistry, Van Nostrand Reinhold, London, 1972.

[32] M. Rosés, E. Bosch, Influence of mobile phase acid-base equilibria on the chromatographic behaviour of protolytic compounds, J. Chromatogr. A. 982 (2002) 130. doi:10.1016/S0021-9673(02)01444-9.

[33] X. Subirats, M. Rosés, E. Bosch, On the effect of organic solvent composition on the $\mathrm{pH}$ of buffered HPLC mobile phases and the $\mathrm{p} K_{\mathrm{a}}$ of analytes - A review, Sep. Purif. Rev. 36 (2007) 231-255. doi:10.1080/15422110701539129.

[34] X. Subirats, M. Rosés, E. Bosch, Buffers for reversed-phase liquid chromatography, Ref. Modul. Chem. Mol. Sci. Chem. Eng. (2015) 1-12. doi:10.1016/B978-0-12409547-2.11547-1.

[35] J. Inczédy, T. Lengyel, A.M. Ure, A. Gelencsér, A. Hulanicki, Compendium of analytical nomenclature, definitive rules 1997, 3rd. ed., Blackell Science, Oxford, 1998.

[36] R.G. Bates, Determination of pH: theory and practice, $2 \mathrm{n}$ ed., Wiley, New York, 1973.

[37] M. Rosés, X. Subirats, E. Bosch, Retention models for ionizable compounds in reversed-phase liquid chromatography. Effect of variation of mobile phase composition and temperature, J. Chromatogr. A. 1216 (2009) 1756-1775. doi:10.1016/j.chroma.2008.12.042.

[38] P. Jandera, Stationary and mobile phases in hydrophilic interaction chromatography: A review, Anal. Chim. Acta. 692 (2011) 1-25. doi:10.1016/j.aca.2011.02.047.

[39] B. Buszewski, S. Noga, Hydrophilic interaction liquid chromatography (HILIC) - a powerful separation technique, Anal. Bioanal. Chem. 402 (2012) 231-247. doi:10.1007/s00216-011-5308-5.

[40] P. Jandera, P. Janás, Recent advances in stationary phases and understanding of retention in hydrophilic interaction chromatography. A review, Anal. Chim. Acta. 967 (2017) 12-32. doi:10.1016/j.aca.2017.01.060.

[41] M. Rosés, C. Ràfols, E. Bosch, Autoprotolysis in aqueous organic solvent mixtures, Anal. Chem. 65 (1993) 2294-2299. doi:10.1021/ac00065a021. 
[42] X. Subirats, E. Bosch, M. Rosés, Retention of ionisable compounds on highperformance liquid chromatography XVIII: $\mathrm{pH}$ variation in mobile phases containing formic acid, piperazine, tris, boric acid or carbonate as buffering systems and acetonitrile as organic modifier, J. Chromatogr. A. 1216 (2009) 2491-2498. doi:10.1016/j.chroma.2009.01.051.

[43] S. Espinosa, E. Bosch, M. Rosés, Retention of ionizable compounds on HPLC. 12. The properties of liquid chromatography buffers in acetonitrile-water mobile phases that influence HPLC retention, Anal. Chem. 74 (2002) 3809-3818. doi:10.1021/ac020012y.

[44] A.J. Alpert, Effect of salts on retention in hydrophilic interaction chromatography, J. Chromatogr. A. 1538 (2018) 45-53. doi:10.1016/j.chroma.2018.01.038.

[45] V. Gold, Glossary of terms used in physical organic chemistry, Pure Appl. Chem. 66 (1994) 1157. doi:10.1351/pac197951081725.

[46] T. Okada, Non-aqueous capillary electrophoretic separation of Bronsted acids as heteroconjugated anions, J. Chromatogr. A. 771 (1997) 275-284. doi:10.1016/S00219673(97)00094-0.

[47] W.M. Haynes (Editor-in-Chief), CRC Handbook of Chemistry and Physics, 97th ed. (2016-2017), CRC Press, 2016.

[48] Bio-Loom. BioByte Corp. Claremont, CA, USA (2018). www.biobyte.com. 